\title{
Lower cognitive performance in 81 -year-old men with greater nocturnal blood pressure dipping
}

\author{
Johan Axelsson \\ Faina Reinprecht \\ Arkadiusz Siennicki-Lantz \\ Sölve Elmståhl \\ Department of Health Sciences, \\ Division of Geriatric Medicine, Lund \\ University, Malmö University Hospital, \\ Malmö, Sweden
}

\begin{abstract}
Abnormal day-to-night blood pressure (BP) pattern have been found to be associated with cerebrovascular damage, yet studies of the elderly 80 years of age and above, for whom the risk pattern may be different due to ageing and age-associated diseases, are lacking. Ninetyseven 81-year-old men underwent ambulatory BP monitoring and were given six cognitive tests, 79 of the men completing the cognitive test battery. The odds ratio (OR) for performing one standard deviation below the mean on any cognitive test was calculated using a forward stepwise logistic regression model, confounding factors being controlled for. Groups defined in terms of day-to-night changes in BP were compared in this respect. Cognitive performance was lower (OR 3.6; $\mathrm{P}=0.017)$ in the group usually described as dippers (10\%-20\% nocturnal drop in systolic BP $[\mathrm{SBP}])$ as compared with nondippers ( $<10 \%$ drop). The tertile with the greatest SBP fall (10.6\%-19.8\%, a range considered as normal among middle aged) showed lowest cognitive performance (OR $4.7 ; \mathrm{P}=0.008)$ as compared with the middle tertile $(5.1 \%-10.5 \%$ drop). The mean nocturnal fall in SBP was 7.4\%, significantly greater in those with lower rather than higher cognitive performance. A nocturnal drop in SBP of $\geq 10 \%$ was associated with lower cognitive performance in these elderly men. The limits to normal dipping appear to be shifted in the direction of a lesser drop in the very elderly.
\end{abstract}

Keywords: aged 80 and over, blood pressure, blood pressure monitoring, circadian rhythm, cognition, cohort study

\section{Introduction}

Blood pressure (BP) normally displays a circadian rhythm, in which a nocturnal drop in systolic blood pressure (SBP) of $10 \%-20 \%$ is usually considered to be normal dipping in middle-aged persons, a lesser fall being described as nondipping, and a greater fall as extreme dipping (Shimada and Kario 1997; Mallion et al 1999; Mancia and Parati 2000). Both nondipping and extreme dipping have shown to be associated with cerebrovascular disease (Shimada et al 1992; Kario et al 2001). Some studies have found nondipping to be a risk marker for cognitive impairment (Kilander et al 1998; van Boxtel et al 1998; Yamamoto et al 2005), while others have found no such association (Cicconetti et al 2004; van Boxtel et al 2006).

There are few studies dealing with circadian blood pressure rhythm in very elderly persons, however, although there are reports of circadian variation diminishing in upper age groups (Jumabay et al 2002; O’Sullivan et al 2003). One can ask whether this is a risk marker for cognitive decline in the very elderly or is instead a beneficial physiological adaptation. A cross-sectional cohort study of 81-year-old men involving use of 24-hour BP monitoring and a cognitive test battery is presented here, exploring the relationship between cognitive functioning and the nocturnal drop in BP. To our knowledge, there has been no study of this sort as yet concerned with persons of such advanced age. 


\section{Materials and methods}

\section{Subjects}

The present study is part of a prospective population study, "Men born in 1914". All men then living in the municipality of Malmö, Sweden born in even months of the year 1914 were invited and 500 out of $560(89 \%)$ participated in the investigation in 1982. In 1995-96 a further investigation was undertaken, in which all the 266 surviving men were invited to participate, 185 of them agreed to this (Reinprecht et al 2003). Of the 136 men for whom ambulatory BP recordings were made, 104 had recordings of sufficient quality, see below. Tests of the cognitive functioning of 97 of these men could be administered, these 97 representing the final study group. No differences were found between the study participants and the excluded subjects on any of the retrieved background factors, a list of which is presented in Table 1. The cognitive test battery consisted of six tests and took about an hour to complete, with 79 of the men were willing to complete all six cognitive tests.

\section{Measures of cognitive functioning}

The cognitive test battery (Table 2) consisted of the following instruments: the Mini Mental State Examination (MMSE) (Folstein et al 1975); a Swedish version of Block Design, which tests ability at visuospatial organization (Wechsler 1981); Synonyms, which measures general verbal ability (Dureman and Sälde 1971); Paired Associates, which tests immediate verbal memory, taken from a Swedish version of the original Verbal Paired Associates of Wechsler (Wechsler 1981); the Digit Symbol Substitution Test, measuring performance speed, visual-motor coordination, concentration, sustained attention and cognitive flexibility (Wechsler 1981); and the Benton Visual Retention Test, measuring immediate visual spatial memory (Benton 1974). The same clinical psychologist tested each of the subjects and the tests were performed before measuring the ambulatory blood pressure.

A cut off point of one standard deviation below the mean value was set for each cognitive test. A lower level of cognitive performance designates a result at the cut off point or below on one or more of the tests in the completed test battery, unless only a single test is considered. Dichotomization of results of the test battery as a whole, rather than of single tests was used to avoid chance findings based on multiple testing.

\section{Ambulatory blood pressure}

Ambulatory BP was monitored during a 24-hour period (Table 3), using noninvasive equipment (Micro AM-5600,
Kontron Instruments), microphonic criteria together with an oscillometric backup system was employed. The accuracy of the recorders was confirmed by simultaneous measurements using a standard mercury sphygmomanometer. BP was measured every 20 minutes during the day (6.20 am to $9.40 \mathrm{pm})$, and every 60 minutes at night (10.00 pm to $6.00 \mathrm{am})$. No restrictions on physical activity were imposed other than those necessary for obtaining accurate readings. Thirty-two subjects were excluded due either to insufficient recording quality, to the daytime recording having deficits during $>3$ consecutive hours or $>6$ hours altogether, or to the nighttime recording having deficits during $>2$ consecutive hours or $>3$ hours altogether. The subjects reported activities and disturbances in a diary. Two of the 97 subjects reported disturbed sleeping and irritation due to the ambulatory BP monitoring, both of them belonging to the group with higher cognitive performance.

Relative day-to-night changes in BP were calculated using the mean daytime and nighttime BP values: (nighttime mean BP-daytime mean BP)/daytime mean BP.

\section{Background variables}

Information on stroke, defined in terms of the ICD-9 classification 430.00-438.99 was retrieved from the Stroke Registry database at the hospital (WHO 1975). Other data on background factors was retrieved when the men were 68 years of age, using a questionnaire for medical history and information on sociodemographic and lifestyle parameters, together with a medical examination, as previously described (Reinprecht et al 2003). Hypertension was defined as the person's having an office $\mathrm{SBP} \geq 160 \mathrm{mmHg}$, diastolic blood pressure (DBP) $>90 \mathrm{mmHg}$ or taking antihypertensive medication (WHO/ISH 1986). Office BP was measured using a manual sphygmomanometer while the subject was in a sitting position. Collected background variables are presented in Table 1.

Dementia was classified according to DSM-IV (APA 1994), the Hachinski ischemic score and scales for Alzheimer's disease and for frontal lobe dementia being used for a differential diagnosis (Hachinski et al 1975; Gustafson and Nilsson 1982).

\section{Ethics}

The study was approved by the local ethics committee at Lund University (LU 111-82). All subjects gave their informed consent.

\section{Statistics}

Differences between groups in their background data were analyzed by use of the Chi square test, Fisher's exact test in 
Table I Background factors at the age of 68 by groups according to cognitive performance at the age of 81 , the history of stroke being obtained for the age of 81

\begin{tabular}{|c|c|c|c|}
\hline Background factor & $\begin{array}{l}\text { Lower cognitive } \\
\text { performance }(n=42)\end{array}$ & $\begin{array}{l}\text { Higher cognitive } \\
\text { performance }(n=37)\end{array}$ & $P$ value \\
\hline Current or former smoking & 31 (74\%) & $27(73 \%)$ & 0.933 \\
\hline Alcohol consumption & & & $0.923^{\mathrm{a}}$ \\
\hline $0 \mathrm{~g} /$ day & $10(24 \%)$ & $8(22 \%)$ & \\
\hline $0,01-19,99 \mathrm{~g} /$ day & $25(60 \%)$ & $24(65 \%)$ & \\
\hline $20-39,99$ g/day & $4(10 \%)$ & $4(11 \%)$ & \\
\hline$\geq 40$ g/day & $3(7 \%)$ & I (3\%) & \\
\hline Physical activity & & & 0.743 \\
\hline Nonvigorous & $32(76 \%)$ & $27(73 \%)$ & \\
\hline Vigorous & $10(24 \%)$ & $10(27 \%)$ & \\
\hline Education & & & $0.079^{a}$ \\
\hline $4-6$ years & $6(14 \%)$ & $4(11 \%)$ & \\
\hline $7-9$ years & $33(79 \%)$ & $24(65 \%)$ & \\
\hline $10-13$ years & $2(5 \%)$ & $5(14 \%)$ & \\
\hline$\geq 14$ years & I (2\%) & $4(11 \%)$ & \\
\hline Civil status & & & $0.177^{b}$ \\
\hline unmarried/noncohabitant & $6(14 \%)$ & $2(5 \%)$ & \\
\hline married/cohabitant & $36(86 \%)$ & 35 (95\%) & \\
\hline Social class & & & 0.212 \\
\hline I & $4(10 \%)$ & $8(22 \%)$ & \\
\hline II & $14(33 \%)$ & $14(38 \%)$ & \\
\hline III & $24(57 \%)$ & $15(40 \%)$ & \\
\hline Diabetes mellitus & I (2\%) & $0(0 \%)$ & $0.526^{\mathrm{b}}$ \\
\hline Hyperlipidemia & $16(38 \%)$ & II (30\%) & 0.434 \\
\hline Obesity & 7 (I7\%) & $4(11 \%)$ & $0.321^{b}$ \\
\hline Hypertension & $24(57 \%)$ & 17 (46\%) & 0.320 \\
\hline Myocardial infarction & $3(7 \%)$ & I (3\%) & $0.357^{\mathrm{b}}$ \\
\hline Angina pectoris & I (2\%) & $0(0 \%)$ & $0.532^{\mathrm{b}}$ \\
\hline Peripheral artery disease & $9(22 \%)$ & $7(20 \%)$ & 0.835 \\
\hline Carotid artery stenosis & $6(15 \%)$ & $9(25 \%)$ & 0.202 \\
\hline Stroke & $3(7 \%)$ & $4(11 \%)$ & $0.428^{b}$ \\
\hline
\end{tabular}

Notes: Data were missing on diabetes mellitus for one man in the lower cognition group, on peripheral artery disease for one man in the lower and two men in the higher cognition group, on carotid artery stenosis for one man in the lower and one man in the higher cognition group. Unless stated otherwise, statistical analyses were performed using the Chi square test; a'Statistical analysis using the Mann-Whitney U-test; 'Statistical analysis using Fisher's exact test.

Table 2 Results of the cognitive tests

\begin{tabular}{lllll}
\hline Test (maximum points) & $\mathbf{n}$ & Mean (SD) & Cutoff point & $\begin{array}{l}\text { No of subjects with } \\
\text { results at or below } \\
\text { the cutoff point } \mathbf{n}(\%)\end{array}$ \\
\hline MMSE (30 p) & & $28.4(1,8)$ & 27 & $23(24)$ \\
Block design (42 p) & 96 & $15.1(5.8)$ & 9 & $18(19)$ \\
Synonyms (30 p) & 94 & $19.8(5.9)$ & 14 & $17(18)$ \\
Paired associates (30 p) & 92 & $16.0(5.8)$ & 10 & $17(18)$ \\
Digit symbol substitution $(90 \mathrm{p})$ & 93 & $29.4(9.9)$ & 20 & $17(20)$ \\
Benton visual retention $(10 \mathrm{p})$ & 86 & $4.5(1.6)$ & 3 & $21(26)$ \\
\hline
\end{tabular}

Abbreviations: SD, standard deviation; MMSE, mini mental state examination. 
Table 3 Blood pressures and nocturnal blood pressure changes for subjects as a whole $(n=97)$

\begin{tabular}{llll}
\hline & $\begin{array}{l}\text { Systolic } \\
\text { pressure }\end{array}$ & $\begin{array}{l}\text { Pulse } \\
\text { pressure }\end{array}$ & $\begin{array}{l}\text { Diastolic } \\
\text { pressure }\end{array}$ \\
\hline \multicolumn{2}{l}{ Ambulatory blood pressure } & & \\
24 -hour $(\mathrm{mmHg})$ & $129(1 \mathrm{I} .9)$ & $55(8.3)$ & $74(10.1)$ \\
Daytime $(\mathrm{mmHg})$ & $131(12.3)$ & $55(8.6)$ & $76(10.4)$ \\
Nighttime (mmHg) & $121(12.7)$ & $53(8.4)$ & $68(10.8)$ \\
Nocturnal blood & $-7.4(6.1)$ & $-2.7(9.7)$ & $-10.0(8.4)$ \\
pressure changes (\%) & & & \\
\hline
\end{tabular}

Note: Data are given as means and standard deviations (SD).

the case of small expected frequencies, or the Mann-Whitney U-test in the case of ordered groups.

Differences between the groups with lower and with higher cognitive performance in their relative changes in nocturnal BP were analyzed using the t-test.

Odds ratios (OR) indicating the degree of relative risk of lower cognitive performance were calculated on the basis of a forward stepwise logistic regression model, with adjustment for the confounders, entered all in one step and listed in Table 1, using a 5\% significance level as criterion for inclusion of variables in the model. Nondippers, dippers and extreme dippers were compared using cut off limits at $10 \%$ and $20 \%$ nocturnal drop in BP, as presented in Table 4 (Shimada and Kario 1997; Mallion et al 1999). Tertiles of the degree of nocturnal fall in SBP and in DBP were calculated for the group of 97 men included in the study, with the middle tertile serving as reference in examining the upper and the lower tertiles.

In a secondary model, similar to the logistic regression model referred to above, subjects with an unchanged or rising nocturnal SBP were compared to a reference group defined as having a $1 \%-9 \%$ drop.

\section{Results}

Dippers, ie, subjects with an SBP drop $\geq 10 \%$, showed significantly lower cognitive performance ( $O R 3.6 ; \mathrm{P}=0.017$ ) than nondippers, those with an SBP drop $<10 \%$ (Table 4). In examining the tertiles of the drop in SBP, subjects with the greatest drop, $10.6 \%-19.8 \%$, were found to have a significantly higher odds ratio (OR 4.7; $\mathrm{P}=0.008$ ) for lower cognitive performance as compared with the middle tertile, where the drop was $5.1 \%-10.5 \%$. No significant relationship to cognitive performance was found for the degree of nocturnal changes in DBP.

Also in the secondary model, in which a $1 \%-9 \%$ SBP drop served as reference, subjects with a drop of $\geq 10 \%$
Table 4 Odds ratios for lower cognitive performance by nocturnal relative blood pressure fall

\begin{tabular}{|c|c|c|c|}
\hline & $\mathbf{n}$ & $\begin{array}{l}\text { Odds ratio } \\
(95 \% \mathrm{Cl})\end{array}$ & $P$ value \\
\hline \multicolumn{4}{|l|}{ Systolic nocturnal fall } \\
\hline \multicolumn{4}{|l|}{ Limits at $10 \%-20 \%$} \\
\hline$<10 \%$ (nondipping) & 49 & I.0 (reference) & - \\
\hline $10 \%-20 \%$ (dipping) & 30 & $3.6(1.3-10.5)$ & 0.017 \\
\hline$>20 \%$ (extreme dipping) & 0 & - & \\
\hline \multicolumn{4}{|l|}{ Tertiles $^{\mathrm{a}}$} \\
\hline$\leq 5.0 \%$ & 23 & $1.5(0.49-4.6)$ & 0.474 \\
\hline $5.1 \%-10.5 \%$ & 29 & I.0 (reference) & - \\
\hline$\geq 10.6 \%$ & 27 & $4.7(1.5-14.6)$ & 0.008 \\
\hline \multicolumn{4}{|l|}{ Diastolic nocturnal fall } \\
\hline \multicolumn{4}{|l|}{ Limits at $10 \%-20 \%$} \\
\hline < I0\% (nondipping) & 31 & $0.74(0.29-1.9)$ & 0.540 \\
\hline 10\%-20\% (dipping) & 40 & I.0 (reference) & - \\
\hline$>20 \%$ (extreme dipping) & 8 & $6.3(0.71-56.2)$ & 0.098 \\
\hline \multicolumn{4}{|l|}{ Tertiles $^{\mathrm{a}}$} \\
\hline$\leq 8.1 \%$ & 24 & $0.62(0.20-1.9)$ & 0.403 \\
\hline $8.2 \%-14.16 \%$ & 26 & I.0 (reference) & - \\
\hline$\geq 14.17 \%$ & 29 & $0.90(0.3 \mathrm{I}-2.6)$ & 0.851 \\
\hline
\end{tabular}

Notes: Odds ratios are adjusted for confounders in a forward stepwise logistic regression model including smoking status, alcohol intake, physical activity, education, civil status, social class, diabetes mellitus, hyperlipidemia, obesity, hypertension, known cardiovascular disease and stroke; ${ }^{2}$ Tertiles were calculated for the group of 97 study participants.

Abbreviation: $\mathrm{Cl}$, confidence interval.

showed a higher odds ratio for lower cognitive performance than the reference group (OR 2.9; $\mathrm{P}=0.040$ ), whereas no significant difference compared with the reference group was found for those with an unchanged or rising nocturnal SBP. The mean SBP for the study population during the 24 hour ambulatory BP recording is presented in Figure 1.

The average day-to-night drop in SBP and DBP drop were $7.4 \%$ and $10.0 \%$, respectively (Table 3 ). In no case was the drop in SBP greater than $20 \%$. Subjects with lower cognitive performance showed a significantly greater nocturnal drop in SBP, whereas there were no appreciable group differences in changes in DBP (Table 5). Also a significantly greater nocturnal drop in PP was found for those with lower cognitive performance. The relative night to day change of PP was associated to belonging to the group with lower cognitive performance, adjusted for the same confounders stated in Table 4 in a logistic regression model, $\mathrm{p}=0.018, \mathrm{~B}=-6.09$.

Dippers, subjects with an SBP drop $\geq 10 \%$, were found to have significantly higher daytime SBP, than nondippers (135 vs $128 \mathrm{mmHg} ; \mathrm{P}=0.007$ ), but significantly lower nighttime SBP (117 vs $123 \mathrm{mmHg}$; $=0.014$ ), the 24-hour 


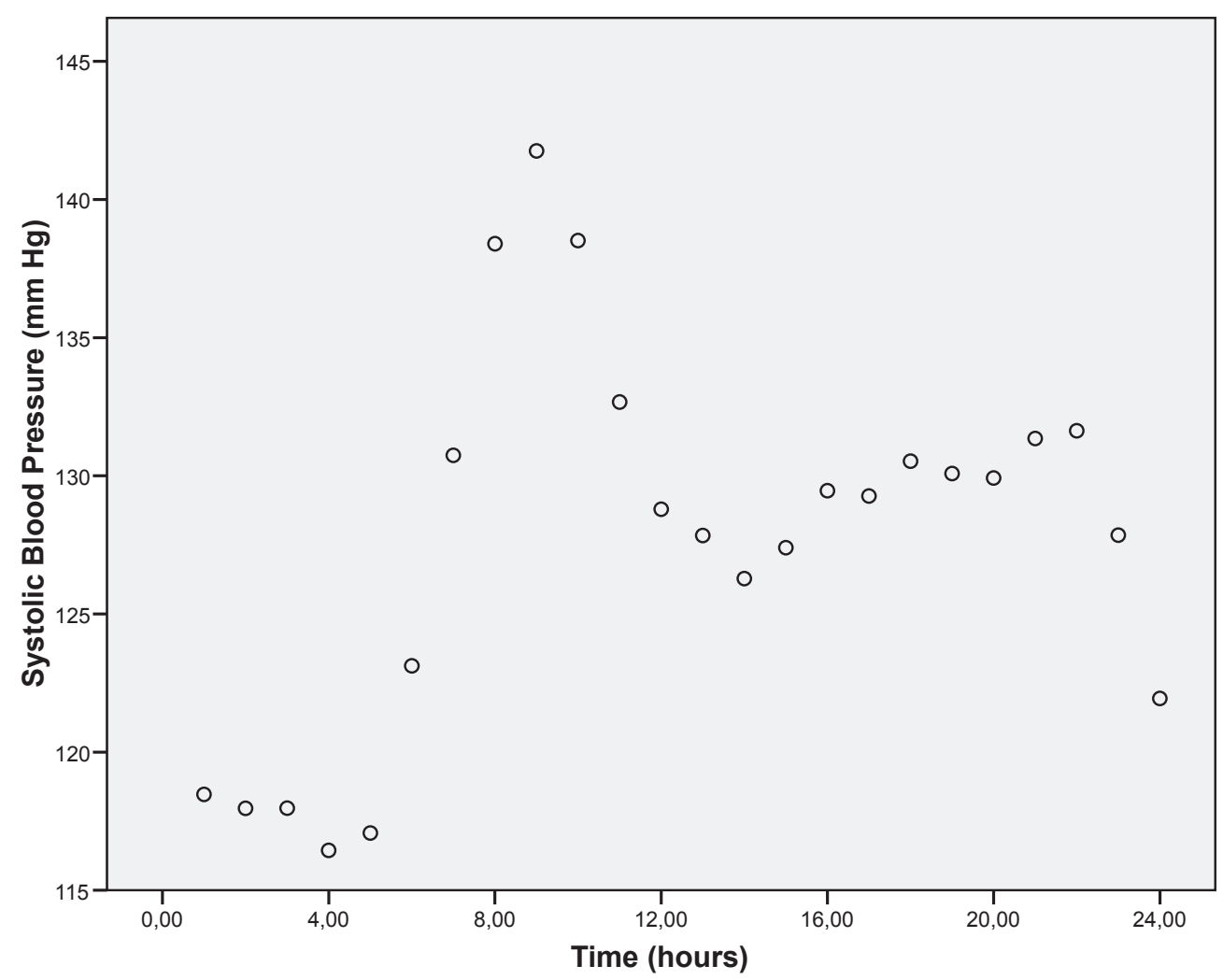

Figure I Mean systolic blood pressure presented hourly for the study population $(n=97)$ of 81 -year-old men assessed during 24 -hour BP monitoring.

SBP having a nonsignificant tendency to be higher (132 vs 127 mmHg; $\mathrm{P}=0.068$ ).

The cognitive test results for subjects as a whole are presented in Table 2. Of the 79 subjects who completed the cognitive test battery, 42 scored at or below the cut-off point for a lower level of cognitive performance on one or more of the tests. No statistically significant differences on background factors were found between groups according to cognitive performance (Table 1).

Table 5 Nocturnal blood pressure changes by groups according to cognitive performance

\begin{tabular}{llll}
\hline & $\begin{array}{l}\text { Lower cognitive } \\
\text { performance } \\
(\mathbf{n}=42) \%\end{array}$ & $\begin{array}{l}\text { Higher cognitive } \\
\text { performance } \\
(\mathbf{n}=37) \%\end{array}$ & P value \\
\hline $\begin{array}{l}\text { Relative change } \\
\text { in SBP }\end{array}$ & $-9.2(6.2)$ & $-6.1(5.6)$ & 0.023 \\
$\begin{array}{l}\text { Relative change } \\
\text { in DBP }\end{array}$ & $-11.8(9.7)$ & $-9.7(7.2)$ & 0.283 \\
$\begin{array}{l}\text { Relative change } \\
\text { in PP }\end{array}$ & $-5.0(9.0)$ & $-0.66(9.9)$ & 0.046 \\
\hline
\end{tabular}

Notes: Data are given as means and standard deviations (SD). Statistical analysis using the $t$-test.

Abbreviations: SBP, systolic blood pressure; DBP, diastolic blood pressure; PP, pulse pressure.
Subjects who completed the cognitive test battery and those who failed to did not differ significantly in their individual cognitive test results. Their average MMSE scores were 28.5 and 27.9 , respectively. There was also no significant difference between the two groups in their average nocturnal fall in BP, 7.7\% and 5.7\%, respectively, for SBP. One participant was diagnosed as having dementia of the Alzheimer type and showed a nocturnal drop in SBP of $10.4 \%$.

Regarding the individual cognitive tests, dippers showed lower cognitive performance on the Synonyms test (OR 5.8; $\mathrm{p}=0.005)$, the MMSE (OR 3.1; $\mathrm{P}=0.043)$, and the Orientation (OR 6.5; $\mathrm{P}=0.013$ ) and Memory (OR 2.4; $\mathrm{P}=0.062$, n.s.) subtests on MMSE.

\section{Discussion}

A nocturnal drop in SBP of $\geq 10 \%$, dipping, was found to be a risk marker for lower cognitive performance in this elderly group of men, although there was no extreme dipper among them with a $>20 \%$ SBP drop. These results differ from earlier findings, but may possibly be explained by the group's consisting entirely of men over 80 years of age.

The relatively small drop in SBP of $7.4 \%$ in the study group as a whole is in line with studies that have shown 
diminished circadian variation with advanced age (Jumabay et al 2002; O'Sullivan et al 2003). It was the middle tertile, with an SBP drop of $5.1 \%-10.5 \%$ that achieved the best results on the cognitive tests. The current notion of normal dipping, defined as a drop in SBP of $10 \%-20 \%$, may not be applicable to persons of advanced age, yet there is a lack of other studies dealing with the impact of circadian BP patterns in persons 80 years of age and above.

A few research groups have examined the relation of circadian BP rhythms to cognition, all in cross-sectional studies. In a study of 70-year-old subjects, Kilander and colleagues (1998) found that those with a nocturnal rise in SBP showed a lower level of cognitive functioning than those with a nocturnal drop. In studying a small group of hypertensive elderly patients, age range 66 to 91 years, Bellelli and colleagues (2004) found lower cognitive performances among subjects with a blunted decline in nocturnal BP. In a study with a wider age range of 43 to 87 years, Yamamoto and colleagues (2005) found cognitive impairment in nondippers as compared with dippers. Van Boxtel and colleagues (1998) also including many younger subjects, the age range being 29 to 81 years, showed similar findings in nondippers. This finding was, however, not replicated in a later study of theirs on hypertensive subjects of similar age range, 40 to 80 years (van Boxtel et al 2006). In two smaller studies, Cicconetti and colleagues $(2003,2004)$ found no association between dipping status and cognitive functioning, yet only patients with newly diagnosed hypertension were included. Kario and colleagues (2001) and Shimada and colleagues (1992) in studying subjects with hypertension, younger participants included, listed the age ranges as $\geq 50$ and 59-83, respectively, finding that those with a 10\%-20\% nocturnal fall in SBP showed a lesser degree of silent cerebrovascular damage. In investigating the incidence of stroke among hypertensives aged $\geq 50$ years, Kario and colleagues (2001) found that those with a rise in nocturnal BP had the worst prognosis and that while those with $a \geq 20 \%$ drop had the second worst prognosis, whereas no significant difference was found between those with a $0 \%-9 \%$ and a 10\%-19\% nocturnal drop. Nakamura and colleagues (1995) concluded that a nocturnal drop in mean BP of $\geq 10 \mathrm{mmHg}$ may increase ischaemic cerebral lesions in patients with cerebrovascular disease and treated with anti-hypertensive drugs (1995). Nevertheless, as already mentioned none of these studies dealt with subjects of as advanced an age as in the present case.

The restriction to male subjects is a limitation in the present study. The men invited can be assumed, however, to be fairly representative of men of their age in the community. Also, we cannot dismiss the possibility of selective mortality among nondippers, as well as among participants who are extreme dippers, especially since no one had a SBP drop of over $20 \%$. Thus, the group studied here could be one having fewer or less serious vascular risk factors than in the population as a whole. Also, the lack of significant results in connection with drops in DBP of over $20 \%$ could be a reflection of simply low statistical power. Thus, we cannot exclude that low DBP might be harmful. In the Rotterdam study, low DBP $<65 \mathrm{~mm} \mathrm{Hg}$ was associated to higher risk of stroke in treated hypertensive patients (Vokó et al 1999). The included and the excluded subjects did not differ appreciably in their background data. Most of the background data used in the study was retrieved some years before, seen as reasonable due to the relatively long time lag to be expected for their possible impact on cognition, with the exception of stroke, which can have a more direct effect. The subjects with lower and higher results, respectively, on the cognitive test battery, did not differ appreciably in their background data, including cardiovascular risk factors, hypertension, diabetes or stroke, which could otherwise have explained the lower performance. Since neuro-radiological examination was not routinely undertaken to determine burden of small vessel disease the presence of strategic infarction and multiple infarction have not been excluded.

The analyses were performed by using tertiles in order to avoid any predefined limits, due to the lack of well accepted clinical definitions. However, the limits used for dipping, 10\% to $20 \%$ was used to facilitate comparisons with other studies. It cannot be excluded that subjects could have had episodes of dipping far beyond the calculated mean values based on the hourly assessments during the night. It could be argued that the extent of nocturnal fall is not representative since the assessment only included 24 hour fall. However, this will not incriminate on the noted finding that a nocturnal drop in SBP of $\geq 10 \%$ was associated to lower cognitive performance since a one day and night assessment merely would increase the risk for a type two error with a falsely negative finding.

There was a nonsignificant tendency for the lower performing group to have fewer years of education, which are, however, controlled for in the logistic regression model, together with other background factors. Those subjects who failed to complete all of the six cognitive tests were found neither to differ significantly in their test results from those who completed the entire cognitive test battery nor to differ significantly from them in their nocturnal changes in BP. The cognitive performance studied seems to be that of a group of persons who were healthier than average for their age, especially since only one subject was diagnosed as having dementia. The mean MMSE score was 28.4, and with the one subject with dementia excluded it was 28.5. This is similar to the baseline value of 28.5 obtained in 
the SCOPE-trial study of 70-89 year old participants after the exclusion of those with dementia (Lithell et al 2003), whereas in the Kungsholmen project, which included subjects within a wider range of cognitive functioning from a communitybased population, the baseline mean MMSE score for 80-84year-olds was 25.3 (Guo et al 1997). Also, the single participant in our study who had dementia did have a greater than average nocturnal drop in SBP but had little impact on the main findings in the study, since he was not included among those completing the cognitive test battery. It thus appears that the findings in our study can be regarded as basically valid for elderly men without dementia. On the other hand, causal relationships cannot be deduced from the present results alone.

Although studies of younger persons have shown nocturnal drop in SBP of $10 \%$ or less to be a risk marker, a drop of this size does not seem to be a risk marker at the age of those participating in the present study, at least not within reasonable limits. The limits to normal dipping in upper age brackets appear to be shifted in the direction of the drop being less than for younger persons. This could be regarded as a beneficial change that tends to prevent cerebral hypoperfusion. More short-term falls in BP have been shown earlier to sometimes have negative consequences. In a five-year follow-up study of healthy elderly women with a mean age 83 at baseline Elmståhl and Rosén (1997) found orthostatic hypotension to be associated with cognitive decline, as determined by EEG measurements. The pathological associations of nocturnal dipping may be indicative of cerebral autoregulation in the elderly being particularly vulnerable. The findings of the present study should be investigated further, whether lower cognitive performance is indicative as a risk factor of cognitive decline, due to moderate nocturnal drop of blood pressure however, preferably in longitudinal studies.

\section{Acknowledgments}

The study was supported by grants from the Swedish Research Council (K2004-27X-15016-01A) and by the Faculty of Medicine at Lund University.

\section{References}

[APA] American Psychiatric Association. 1994. Diagnostic and statistical manual of mental disorders: DSM-IV. 4th ed. Washington DC: American Psychiatric Press Inc.

Bellelli G, Frisoni GB, Lucchi E, et al. 2004. Blunted reduction in night-time blood pressure is associated with cognitive deterioration in subjects with long-standing hypertension. Blood Press Monit, 2:71-6.

Benton A. 1974. The revised visual retention test: clinical and experimental applications. 4th ed. New York: Psychological Corporation.

Cicconetti P, Ciotti V, Monteforte G, et al. 2003. Circadian blood pressure pattern and cognitive function in newly diagnosed older hypertensives. Blood Press, 3:168-74.
Cicconetti P, Ciotti V, Tafaro L, et al. 2004. Event-related brain potentials in elderly dippers and nondippers with recently diagnosed hypertension. Hypertens Res, 8:581-8.

Dureman I, Sälde H. 1971. DS-batteriet. Manual (in Swedish). Stockholm: Psykologiförlaget.

Elmståhl S, Rosén I. 1997. Postural hypotension and EEG variables predict cognitive decline: results from a 5-year follow-up of healthy elderly women. Dement Geriatr Cogn Disord, 3:180-7.

Folstein MF, Folstein SE, McHugh PR. 1975. "Mini-mental state". A practical method for grading the cognitive state of patients for the clinician. J Psychiatr Res, 3:189-98.

Guo Z, Fratiglioni L, Winblad B, et al. 1997. Blood pressure and performance on the Mini-Mental State Examination in the very old. Crosssectional and longitudinal data from the Kungsholmen Project. Am J Epidemiol, 12:1106-13.

Gustafson L, Nilsson L. 1982. Differential diagnosis of presenile dementia on clinical grounds. Acta Psychiatr Scand, 3:194-209.

Hachinski VC, Iliff LD, Zilhka E, et al. 1975. Cerebral blood flow in dementia. Arch Neurol, 9:632-7.

Jumabay M, Ozawa Y, Kawamura H, et al. 2002. Ambulatory blood pressure monitoring in Uygur centenarians. Circ J, 1:75-9.

Kario K, Pickering TG, Matsuo T, et al. 2001. Stroke prognosis and abnormal nocturnal blood pressure falls in older hypertensives. Hypertension, 4:852-7.

Kilander L, Nyman H, Boberg M, et al. 1998. Hypertension is related to cognitive impairment: a 20-year follow-up of 999 men. Hypertension, 3:780-6.

Lithell H, Hansson L, Skoog I, et al. 2003. The Study on Cognition and Prognosis in the Elderly (SCOPE): principal results of a randomized double-blind intervention trial. J Hypertens, 5:875-86.

Mallion JM, Baguet JP, Siche JP, et al. 1999. Clinical value of ambulatory blood pressure monitoring. J Hypertens, 5:585-95.

Mancia G, Parati G. 2000. Ambulatory blood pressure monitoring and organ damage. Hypertension, 5:894-900.

Nakamura K, Oita J, Yamaguchi T. 1995. Nocturnal blood pressure dip in stroke survivors. A pilot study. Stroke, 8:1373-8.

O'Sullivan C, Duggan J, Atkins N, et al. 2003. Twenty-four-hour ambulatory blood pressure in community-dwelling elderly men and women, aged 60-102 years. J Hypertens, 9:1641-7.

Reinprecht F, Elmståhl S, Janzon L, et al. 2003. Hypertension and changes of cognitive function in 81-year-old men: a 13-year follow-up of the population study "Men born in 1914", Sweden. J Hypertens, 1:57-66.

Shimada K, Kario K. 1997. Altered circadian rhythm of blood pressure and cerebrovascular damage. Blood Press Monit, 6:333-8.

Shimada K, Kawamoto A, Matsubayashi K, et al. 1992. Diurnal blood pressure variations and silent cerebrovascular damage in elderly patients with hypertension. J Hypertens, 8:875-8.

van Boxtel MP, Gaillard C, Houx PJ, et al. 1998. Is nondipping in $24 \mathrm{~h}$ ambulatory blood pressure related to cognitive dysfunction? J Hypertens, 10:1425-32.

van Boxtel MP, Henskens LH, Kroon AA, et al. 2006. Ambulatory blood pressure, asymptomatic cerebrovascular damage and cognitive function in essential hypertension. J Hum Hypertens, 1:5-13.

Vokó Z, Bots ML, Hofman A, et al. 1999. J-shaped relation between blood pressure and stroke in treated hypertensives. Hypertension, 34:1181-5.

Wechsler D. 1981. Wechsler Adult Intelligence Scale - revised manual. New York: Psychological Corporation.

[WHO] World Health Organization. 1975. International Classification of Diseases, Injuries and Causes of Death, 9th revision (ICD-9). Geneva: World Health Organization.

[WHO/ISH]. World Health Organization, International Society of Hypertension. 1986. 1986 guidelines for the treatment of mild hypertension: memorandum from a WHO/ISH meeting. J Hypertens, 3:383-6.

Yamamoto Y, Akiguchi I, Oiwa K, et al. 2005. The relationship between 24-hour blood pressure readings, subcortical ischemic lesions and vascular dementia. Cerebrovasc Dis, 5:302-8. 
